\title{
Nasolacrimal way of stem cells implantation
}

\begin{abstract}
Hypothesis on migration of stem cells to injured brain region after introduction of stem cells into nasolacrimal duct has been experimentally verified on Wistar rats $(n=7)$. Fluorescent stem cells have been detected in the injured region of frontal cerebral cortex using confocal microscopy in 20 hours after implantation of mesenchymal stem cells into nasolacrimal duct of rats.
\end{abstract}

Keywords: brain trauma, cell technology, nasolacrimal implantation, stem cells

\author{
Volume 8 Issue 2 - 2018 \\ Vladimir Kulchitsky,' Alexandra Zamaro,' \\ Svetlana Pashkevich,' Timur Sushko,' \\ Stanislav Koulchitsky² \\ 'Institute of Physiology, National Academy of Sciences of \\ Belarus, Belgium \\ ${ }^{2}$ Liege University, Liege, Belgium
}

Correspondence: Vladimir Kulchitsky, Institute of Physiology,

National Academy of Sciences of Belarus, Belgium,

Email vladi@fizio.bas-net.by

Received: February 15, 2018| Published: March 27, 2018
Abbreviations: FITC, fluorescein isothiocyanate; MSC, mesenchymal stem cells; SC, stem cells

\section{Introduction}

Modern cell technologies quickly became the usual approach in complex treatment of patients with various diseases of the brain and spinal cord. ${ }^{1-4}$ There are systemic and local methods as the dominant ways of introducing stem cells (SC) in traumas, strokes and other destructive processes. Intravenous and intra-arterial ways of introducing SC suspension are the most popular among systemic methods. ${ }^{5,6}$ Specialists also use local methods of SC delivery to the brain, which include skull trepanation, laminectomy, and the SC introduction into cerebrospinal fluid. ${ }^{7,8}$ Additional surgical interventions (trepanation, laminectomy, suboccipital or lumbar puncture), as well as damage of significant number of SC on the way from the site of injection to the area of destruction are the disadvantages of these methods. In this regard, scientists offer alternative ways of SC introduction to the brain and spinal cord.

Specialists develop methods for correcting pathological processes in the brain after inserting a suspension of SC into the submucosa of nasal cavity. ${ }^{9}, 10 \mathrm{SC}$ migrate along the nerve fibers of olfactory nerve from nasal cavity to the site of brain destruction. ${ }^{11}$ It is worth noting that the intranasal method is based on the use of natural migration of immunocompetent and tumor cells beside the cranial nerves. ${ }^{12}$ SC drift along the olfactory nerve mostly into the anterior cranial fossa, where the central nuclei of the olfactory nerve are located..$^{11,13}$ The Ethics Committee of the Institute of Physiology of the National Academy of Sciences of Belarus allows the injection of SC into the submucosal layer of the nasal cavity only under anesthesia to avoid possible problems. In this regard, repeated additional anesthesia in patients with impaired brain function is a negative side for this method. The authors of the article decided to level this disadvantage. It was necessary to suggest an alternative method, which has a minimum of side effects.

We decided to verify our hypothesis on possible SC migration to injured brain region after mesenchymal stem cells (MSC) introduction into nasolacrimal duct. It is known that clinicians widely apply introduction of various drugs into nasolacrimal sac in humans without anesthesia. The exit from the nasolacrimal duct is located in the mucosa of inferior turbinate of nasal cavity. Therefore, in patients it is feasible to carry out the dosed delivery of stem cells to the receptive region of the olfactory nerve without anesthesia. Unfortunately, the search for "stem cell nasolacrimal implantation" and "stem cell nasolacrimal application" found no matching documents in PubMed.

We verified the method of SC delivery via nasolacrimal duct of rats in order to test this hypothesis. MSC were isolated from adipose tissue in female rats and cultivated for 6 days for cell mass gain at the early stage of the experiment. The experiments were performed on Wistar rats $(\mathrm{n}=7)$ anesthetized with ketamine-xylazine-acepromazine cocktail $(55.6,5.5$, and $1.1 \mathrm{mg} / \mathrm{kg}$, respectively) at the close of cultivation stage. Aspiration was used to remove $0.3 \mathrm{~mm}^{3}$ of brain tissue in a stereotactic apparatus after trepanation in the right frontal region. The surgeon then introduced $100 \mu \mathrm{l}(10,000$ cells $)$ of MSC suspension into the right nasolacrimal duct using Hamilton syringe. MSC were pre-labeled with CD90 and FITC by the traditional method. ${ }^{14}$ Eye surface has been washed with normal saline in 10 minutes after MSC application. Follow-up did not reveal any side effects from animals' eyes and behavior. Horizontal brain sections (100 $\mu \mathrm{m}$ in thickness) have been made using freezing microtome in twenty hours after the surgery. Then the analysis of fluorescent stem cells distribution along the edge of the trauma have been performed using the confocal microscope (Zeiss AxioVert 200M fluorescence microscope with Zeiss AxioCam HRm CCD camera) (Figure 1). Fluorescent signal was registered within $515-565 \mathrm{~nm}$ as selected by Zeiss FITC filter set.

Figure 1 shows trail of fluorescent elements along the border of injured brain region in right frontal cerebral area. Therefore, MSC begin centralizing in the injured brain region in 20 hours after their implantation into nasolacrimal duct. Thus, the hypothesis on the feasibility of nasolacrimal route usage for introduction of stem cells into the brain to restore brain functions after trauma or stroke was positively verified under experimental conditions. 


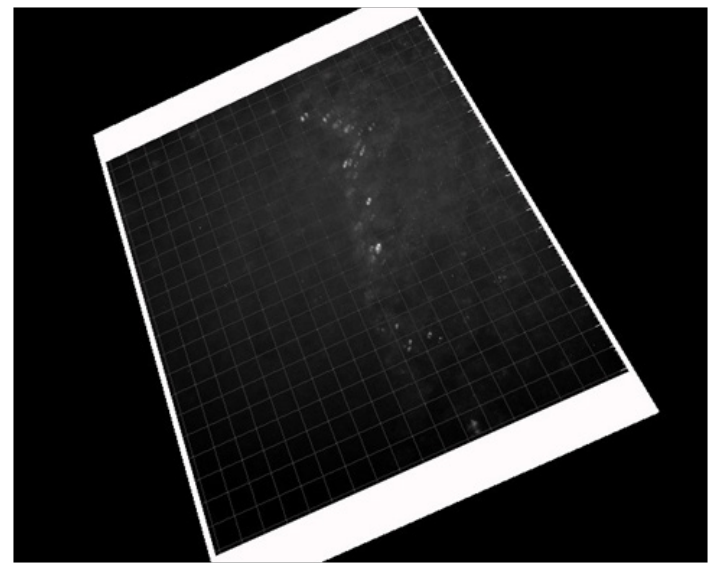

Figure I Three-dimensional model of stem cells distribution at the edge of injured brain region. Each square side is $10 \mu \mathrm{m}$ in length.

\section{Acknowledgements}

This pooled analysis was funded by OOO Synergy.

\section{Conflict of interest}

All listed authors concur with the submission of the manuscript; all authors have approved the final version. The authors have no financial or personal conflicts of interest.

\section{References}

1. Kenmuir CL, Wechsler LR. Update on cell therapy for stroke. Stroke and Vascular Neurology. 2017;2(2):59-64.

2. Sarkar P, Rice CM, Scolding NJ. Cell Therapy for Multiple Sclerosis. CNS Drugs. 2017;31(6):453-469.

3. Gennai S, Monsel A, Hao Q, et al. Cell-based therapy for traumatic brain injury. Br J Anaesth. 2015;115(2):203-212.
4. Vaquero J, Zurita M. Cell transplantation in paraplegic patients: the importance of properly assessing the spinal cord morphology. Clinical Transplantation. 2013;27(6):968-971.

5. Prasad K, Sharma A, Garg A, et al. Intravenous autologous bone marrow mononuclear stem cell therapy for ischemic stroke: a multicentric, randomized trial. Stroke. 2014;45(12):3618-3624.

6. Silachev DN, Plotnikov EY, Babenko VA, et al. Intra-Arterial Administration of Multipotent Mesenchymal Stromal Cells Promotes Functional Recovery of the Brain After Traumatic Brain Injury. Bulletin of Experimental Biology and Medicine. 2015;159(4):528-533.

7. Chen DC, Lin SZ, Fan JR, et al. Intracerebral implantation of autologous peripheral blood stem cells in stroke patients: a randomized phase II study. Cell Transplant. 2014;3(12):1599-1612.

8. Mendonça MV, Larocca TF, de Freitas Souza BS, et al. Safety and neurological assessments after autologous transplantation of bone marrow mesenchymal stem cells in subjects with chronic spinal cord injury. Stem Cell Res Ther. 2014;5(6):126.

9. Li YH, Feng L, Zhang GX, et al. Intranasal delivery of stem cells as therapy for central nervous system disease. Exp Mol Pathol. 2015;8(2):145151

10. Ninomiya $\mathrm{K}$, Iwatsuki $\mathrm{K}$, Ohnishi $\mathrm{Y}$, et al. Intranasal delivery of bone marrow stromal cells to spinal cord lesions. J Neurosurg spine. 2015;23(1):111-119.

11. Stukach YP, Shanko YG, Kulchitsky VA. Experimental substantiation of stem cells delivery to the brain through cerebral nerves endings. Biological motility. 2016;232-235.

12. Liebig C, Ayala G, Wilks JA, et al. Perineural invasion in cancer: a review of the literature. Cancer. 2009;115(15):3379-3391.

13. Danielyan L, Schäfer R, von Ameln-Mayerhofer A, et al. Intranasal delivery of cells to the brain. Eur J Cell Biol. 2009;8(6):315-324.

14. Stukach Y. Stem cells migration to the brain through cranial nerves endings. The Euro Biotech J. 2017;(1):99-100. 